\title{
Investigation of the ESP cleaning efficiency of the flue gases in the wide range of $R e$ numbers
}

\author{
R. Poškas*, A. Sirvydas**, P. Poškas***, V. Šimonis****, J. Jankauskas***** \\ *Lithuanian Energy Institute, Breslaujos 3, LT-44403 Kaunas, Lithuania, E-mail: Robertas.Poskas@lei.lt \\ **Lithuanian Energy Institute, Breslaujos 3, LT-44403 Kaunas, Lithuania, E-mail: Arunas.Sirvydas@lei.lt \\ ***Lithuanian Energy Institute, Breslaujos 3, LT-44403 Kaunas, Lithuania,E-mail: Povilas.Poskas@lei.lt \\ ****Lithuanian Energy Institute, Breslaujos 3, LT-44403 Kaunas, Lithuania, E-mail: Vytautas.Simonis@lei.lt \\ *****Lithuanian Energy Institute, Breslaujos 3, LT-44403 Kaunas, Lithuania, E-mail: Jurgis.Jankauskas@lei.lt \\ cross ${ }^{r e f}$ http://dx.doi.org/10.5755/j01.mech.23.1.14226
}

\section{Introduction}

Compared to other types of fuel, biomass (biofuel) is considered to have a great potential as a fuel source with acceptable cost [1]. Many countries use biofuel (e.g., wood, straw, grains) for centralised heating, medium and large-scale production of process heat, and heat for electricity production. The use of biofuel has been increasing in Europe over the last several years and the reason for that is the least negative impact on the environment compared to other renewable energy sources [2, 3]. Biofuel is also used in many small-scale household furnaces.

Biomass combustion systems have achieved comparably low levels of gaseous emissions. However, $\mathrm{NO}_{\mathrm{x}}$ problems are still important [4]. Concerning particulate emissions, especially emissions of fine particulates, it is still a disadvantage compared to oil and natural gas fired systems [5], [6]. According to studies [7-10], the total amount of particulate emissions from modern residential biomass furnaces that are fired using wood logs or wood pellets (power $\leq 40 \mathrm{~kW}$ ) is significantly lower compared to the old systems.

In order to avoid negative effects on health, EU Council directive 1999/30/EC requires to take measurements and in that way ensures that concentrations of PM10 (i.e. particles up to $10 \mu \mathrm{m}$ in diameter) in the ambient air should not exceed the limiting values. There are also general strategies for reduction of PM10 concentrations that aim to decrease PM2.5 concentrations (particles up to 2.5 $\mu \mathrm{m}$ in diameter) as well. Usually flue gases are filtered (cleaned) in multicyclones or fibre filters before discharge from power plants into the atmosphere. Yet, in the case of fine and ultrafine particulates, the filters of such type do not show high effectiveness, thus electrostatic precipitators (ESP) are used [11]. Low aerodynamic drag and high efficiency are the advantages of electrostatic precipitators [12]. Therefore electrostatic precipitators are one of the most commonly employed particulate control devices for collecting particulate emissions from boilers, incinerators and from many other industrial processes. Hence, many studies examine performance, operation and improvement of industrial precipitators [13-16].

As well as the industrial area, private houses have increased the use of biofuel. Hence, the amount of generated solid particles and gaseous emissions also grows due to small combustion appliances. As an attempt to solve the environmental protection problems, the EN303-5:2012 standard issued in 2012 sets the requirements for production of combustion appliances with a nominal heat output up to $500 \mathrm{~kW}$. Generally speaking, this standard aims to reduce the emissions from the boilers and increase their efficiency. Limiting emission values of $\mathrm{SO}_{2}, \mathrm{NO}_{x}, \mathrm{CO}$, organic gaseous carbon and solid particles are also set in the standard depending on the boiler class. There are three classes: 3, 4, and 5 (in comparison to the previous version of the standard, boiler classes 1 and 2 now are cancelled); the higher the class, the stricter the requirements.

In order to reduce emissions from small-scale boilers to the levels even lower than specified in Standard EN303-5:2012, there are special (voluntary) standards, guidelines applied in some countries (Germany, Austria, Switzerland, etc.). Some Nordic countries apply the special environmental protection standard "The Swan" (SW-N). Finland regulates limiting emission values based on the best available technology (BT-F) [17].

The market already offers electrostatic precipitators for small-scale combustion appliances; however, there is a lack of suitable analysis of their performance, and there are very few studies on installation of pollution control devices for small-scale biomass-fired appliances [18]. In order to avoid air quality problems caused by biomass combustion, an inexpensive, compact and simple solution is preferable for small-scale application. In few studies [19-24], electrostatic precipitators were specifically designed and constructed for removal of particulate matter from biofuel burning in small combustors. Their electrical characteristics and the total collection efficiency were evaluated. The investigated electrostatic precipitators resulted in total collection efficiencies from $70 \%$ to $90 \%$.

In [5] the survey on the most modern precipitation units for residential biofuel combustion systems was presented. 13 electrostatic precipitators, 2 catalytic converters, 2 ceramic filters and 3 condensing heat exchangers were evaluated in the survey. The results showed that the ESP technology is the approach with the highest potential for small-scale biofuel combustion. The combustion conditions for most of the ESPs during the tests were good or at least acceptable. However, the number of long term test runs was very small; hence, there are no sufficient data on the availability and applicability of the investigated appliances. The result analysis showed that the total precipitation efficiency of $50 \%-85 \%$ could be achieved, and it depends on 
the combustion technology (new or old) and the utilised fuel.

Thus, the literature review shows that there are many investigations (including industrial installations) related to assessment of the total collection efficiency of the ESP. However, there is only limited number of investigations showing fractional collection efficiency in the ESP.

In this study fractional and total collection efficiency of solid particles from a class 3 modern small power boiler ( $50 \mathrm{~kW}$ nominal capacity) are investigated, and impact of the polarity of the electrodes on the collection efficiency of the electrostatic precipitator intended for smallscale heating appliances combusting biofuel are studied in wide range of $R e$ numbers. The obtained results enrich the rather limited knowledge in the area of the use of electrostatic precipitation for cleaning small streams of flue gases with rather low concentration of dust.

\section{Experimental methods}

The experimental setup used for the investigation of the ESP characteristics is presented in Fig. 1. Flue gases were generated by incinerating the fuel in the boiler. A commercial boiler of class 3 (EN303-5:2012) was used. This boiler is an automatic device whose rated power is $50 \mathrm{~kW}$. Incineration materials for this boiler could be pellets, wood, pea-coal and cereals. The fuel and air for combustion were supplied considering the set boiler power. During the experiments, only wood pellets made from different kinds of wood sawdust were incinerated. Temperature of the flue gas exhausted from the boiler was $\sim 150^{\circ} \mathrm{C}$. The chimney draft was $\sim 25 \mathrm{~Pa}$ (the flue gas exhauster automatically kept the draft value). The flue gas flow rate was $\sim 177 \mathrm{~m}^{3} / \mathrm{h}$. The diameter of the insulated flue gas pipe was $180 \mathrm{~mm}$ and the total height was $\sim 15 \mathrm{~m}$. Discharges of flue gases into the atmosphere are always at some distance from the boiler and the measurements there are the most important; therefore, for the measurement of the particles, the distance of $\sim 8 \mathrm{~m}$ from the ESP was selected.

The ESP (see Fig. 2) for the laboratory tests was designed and manufactured at the Lithuanian Energy Institute. The external dimensions of the ESP frame made from carbon steel angle bars was $\sim 530 \times 365 \times 1890 \mathrm{~mm}$. The inlet was positioned at the upper part of the ESP and the outlet was positioned at its lower part. Inside the frame, between the two holding plates, three pairs of pipes (i.e. six collecting electrodes; diameter $d=120 \mathrm{~mm}$ each, length $l \approx 1000 \mathrm{~mm}$ ) made from stainless steel were installed. So, the collection area of one electrode was $\sim 0.38 \mathrm{~m}^{2}$. At the centres of each pipe, a nichrome wire (discharge electrode) of $0.2 \mathrm{~mm}$ diameter was stretched between special holders. Special steel springs ensured the tension of the electrodes; and the distance between the discharge electrodes in each pair was $~ 160 \mathrm{~mm}$.

In order to avoid flue gas leakages between the holding plates and the collecting electrodes, the contact perimeters between them were sealed using ceramic paper.

During the experiments each pair of the discharge electrodes was connected to separate Glassman Series FR high voltage power supply units, whose output voltage was in the $0-30 \mathrm{kV}$ range. Both negative and positive potentials of the high voltage power supply units were used. The pe- culiarities of the ESP collecting efficiency were revealed using a different number of collecting electrodes (one, two and six). This allowed having Re numbers 25000, 12500 and 4200 (at velocities $u=4.32,2.16$ and $0.72 \mathrm{~m} / \mathrm{s}$ ), respectively. $R e$ number was defined as $R e=u d / v$, where $v$ - kinematic viscosity of the flue gases defined based on [25] recommendations. When one electrode was used, the tubes with the remaining electrodes were sealed using special plates, and the flue gases flew only through the open pipe. When two collecting electrodes were used, the remaining four were sealed; when six electrodes were used, all the electrodes were opened.

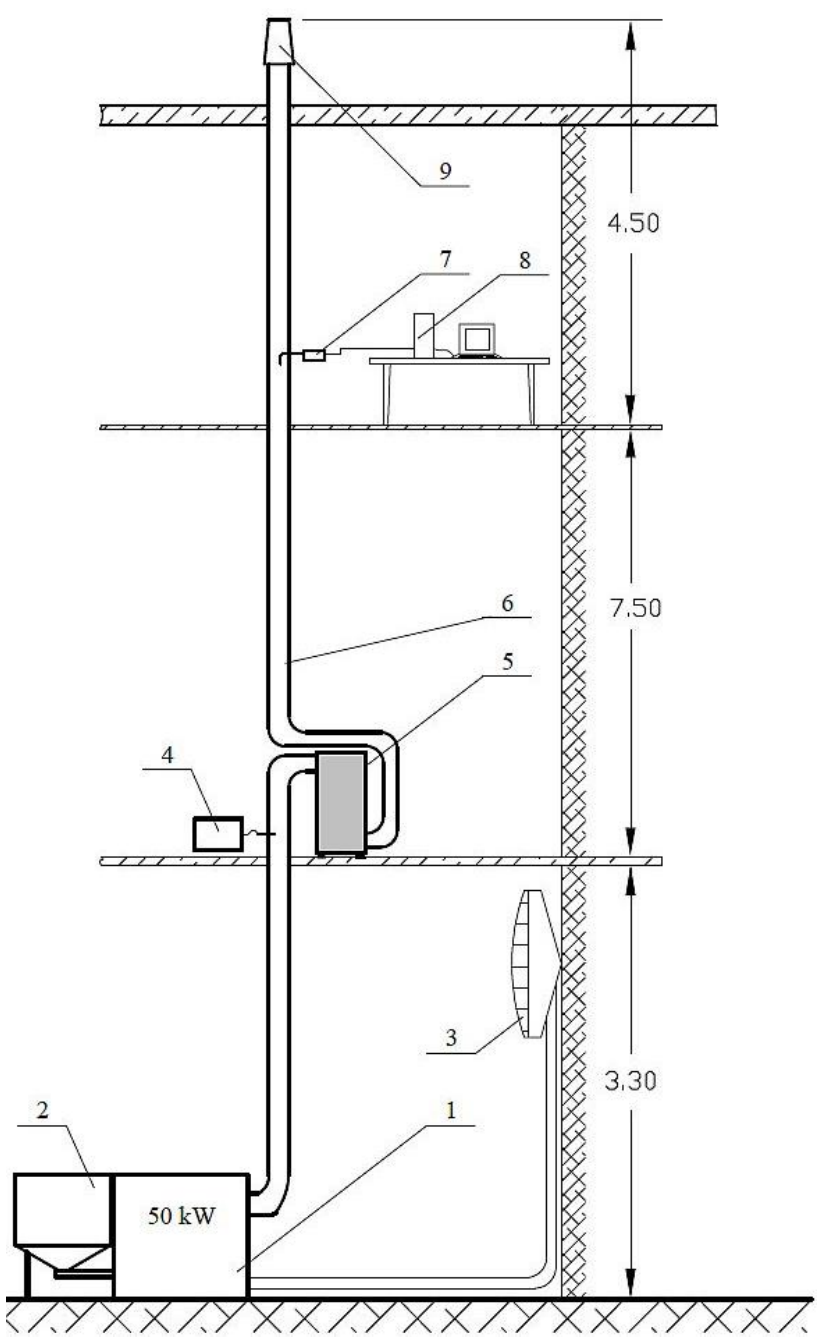

Fig. 1 Experimental setup (not to scale): 1 - boiler; 2 - fuel bunker; 3 - heat exchanger; 4 -flue gas analyzer; 5 - electrostatic precipitator; 6 - flue gas pipe (chimney); 7 - infrared particle sizer; 8 - data acquisition system; 9 - flue gas exhauster

In the chimney segment between the ESP and the flue gas exhauster, an infrared particle sizer (IPS-K, made by "Kamika instruments") was installed (Fig. 1, pos. 7). The IPS-K is designed in accordance with Standard EN13284 and it is an instrument for direct measurements of total dust concentration and concentration of dust fractions in flue gas channels. The particle sizer is composed of a measuring head and an electronic computer-controlled measurement unit. Operation of an IPS-K is based on the principle of light scattering. The particles moving through 
the measurement zone scatter infrared light. An electric pulse proportional to the diameter of the spherical particle is generated by each particle moving through the measurement zone. The analyser is calibrated with spherical particles in accordance with standards and attestations of Thermo Fisher Scientific, Inc. (USA). For non-spherical particles, the amplitude of the pulse depends on the particle's orientation in the measurement zone. Thus, an IPS-K sizer ensures only 1D measurements and can measure particles in the $0.4-300 \mu \mathrm{m}$ range (this range is divided into four subranges). An IPS-K also measures flue gas temperature (up to $250^{\circ} \mathrm{C}$ ), concentration of solid particles (up to $200 \mathrm{mg} / \mathrm{m}^{3}$ ) flue gas velocity and flow rate (from 50 to $500 \mathrm{~m}^{3} / \mathrm{h}$ ). The software for IPS-K management does automatic calculations of particle concentrations in a cubic meter of flue gases.

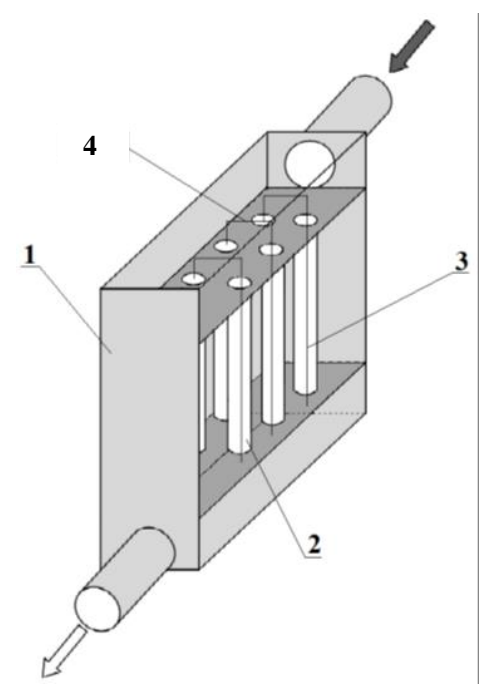

Fig. 2 Electrostatic precipitator (not to scale): 1 - frame; 2 -stainless steel pipes (collecting electrodes); 3 - discharge electrodes; 4 - high voltage supply

Isokinetic suction of the gases was performed in order to ensure undisturbed stream of the flue gases flowing into the intake nozzle of the sizer's measuring head and to have representative measuring. So, the suction of the gases into the intake nozzle was automatically kept by the IPS-K to be the same (or very similar) as the velocity and direction of the flue gases in the chimney. The measuring head of the IPS-K was also equipped with a special holder for the filter, which can be used for the determination of concentration of solid particles by gravimetric method as specified in Standard EN13284-1:2001. In principle, the total concentration can also be defined from optical measurements but in order to avoid problems related with the uncertainty of the density of the particles, in this study the total concentration was measured by gravimetric method only.

A flue gas analyzer IMR2000 was used in the experiments to measure the gaseous emissions from the boiler and the excess air values. The obtained values of the emissions $\left(\mathrm{CO}_{2}, \mathrm{CO}\right.$ and excess air value) allowed judging the completeness of the combustion process. Besides, measured $\mathrm{O}_{2}$ value in the flue gases was used to recalculate the concentrations of the gaseous emissions and the emissions of solid particles for the reference oxygen value. In this way it was easier to compare them with data of other investigations.

All the measurements during the experiments were performed under stable combustion conditions.

\section{Results and their analysis}

First of all, the total concentration of solid particles was measured using the IPS-K (see Fig. 1, pos. 5), and the result presented in Table I is based on the gravimetric method. The sampling, i.e. suction of gases via the filter, lasted for 30 minutes. A rather low concentration of the solid particles was obtained: $\sim 13 \mathrm{mg} / \mathrm{Nm}^{3}$ (the limiting values are much higher) (Table 1). Due to configuration of the experimental setup (see Fig. 1), some amount of particles can be lost in the ESP and chimney bends. In comparison concentration of the solid particles in the case of wood pellets combustion in low capacity water boilers determined by [26] was $21.5 \mathrm{mg} / \mathrm{Nm}^{3}$.

Table 1

Emissions from the boiler. Measured emissions are presented for the reference value of $\mathrm{O}_{2}-10 \%$

\begin{tabular}{|c|c|c|c|c|c|c|}
\hline & $\begin{array}{c}\mathrm{CO}_{2} \\
\%\end{array}$ & $\begin{array}{c}\mathrm{CO} \\
\mathrm{mg} / \\
\mathrm{Nm}^{3}\end{array}$ & $\begin{array}{l}\mathrm{NO} \\
\mathrm{mg} / \\
\mathrm{Nm}^{3}\end{array}$ & $\begin{array}{l}\mathrm{NO}_{2} \\
\mathrm{mg} / \\
\mathrm{Nm}^{3}\end{array}$ & $\begin{array}{l}\mathrm{SO}_{2} \\
\mathrm{mg} / \\
\mathrm{Nm}^{3}\end{array}$ & $\begin{array}{l}\mathbf{P M} \\
\mathbf{m g} / \\
\mathrm{Nm}^{3}\end{array}$ \\
\hline Measured & 10.5 & 245 & 103 & 0 & 4.4 & 12.8 \\
\hline $\begin{array}{l}\text { EN303- } \\
5: 2012^{1} \\
\end{array}$ & - & 3000 & - & - & - & 150 \\
\hline BT-F ${ }^{3}$ & - & - & $125^{2}$ & - & 375 & - \\
\hline SW-N ${ }^{3}$ & - & 1000 & - & - & - & 70 \\
\hline
\end{tabular}

1 - recommended limits for a class 3 boiler

2 - provided value is for $\mathrm{NO}_{\mathrm{x}}$

3 - recommended limits from [17]

So, basing on the measured gaseous emissions from the boiler (Table 1), it can be concluded that during the experiments the combustion process was complete and the gaseous emissions were smaller than the recommended limiting values provided in the regulations.

Although releases of solid particles from modern boilers are low, a combination of such boiler with an electrostatic precipitator may reduce the releases of particles to the minimum.

Relative quantity of the solid particle distribution in the flue gases depending on the applied voltage to the discharge electrodes of the ESP is presented in Fig. 3.

The measurements for the highest $R e$ number $(R e=25000)$ demonstrate that when no voltage was applied (Fig. 3, $0 \mathrm{kV}$ ), the diameters of the solid particles in the flue gases were mainly from 0.4 to $\sim 20 \mu \mathrm{m}$. Fig. 3 shows that the highest quantity of the particles in the distribution (peak in Fig. 3) is at the diameter of about 4-5 $\mu \mathrm{m}$ (i.e. similar as determined in [27]). The peak value (100\%) in Fig. 3 corresponds to the concentration of the particles equal to $\sim 5.6 \times 10^{5}$ in a cubic meter.

When the voltage to the ESP was increased till $2 \mathrm{kV}$, the distribution of the particles practically remained the same. From the voltage of $4 \mathrm{kV}$, a slight decrease in quantity of the particles was observed in the case of a negative potential (Fig. 3, a). The decrease was clearly expressed in the range of particle diameter between $\sim 2.5-$ $20 \mu \mathrm{m}$. This means that the electrostatic forces start to act, 
and some particles are already captured on the collecting electrodes (i.e. stainless steel pipes, see Fig. 2). At the voltage of $\sim 6 \mathrm{kV}$, a sudden decrease of a relative number of particles is noticed. This means that from this voltage the significant ionization of the flue gases around the discharge electrode, and the particles in the flue gases are charged by the ions. The charged particles are attracted and collected on the collecting electrodes and therefore, in this case, a significant decrease of particle quantity is obtained. Further voltage increase till $10 \mathrm{kV}$ showed some tendency for the particle quantity decrease. When the voltage increased till $12 \mathrm{kV}$, there was no notable affect observed, only some very small quantities of the particles were not captured by the ESP.

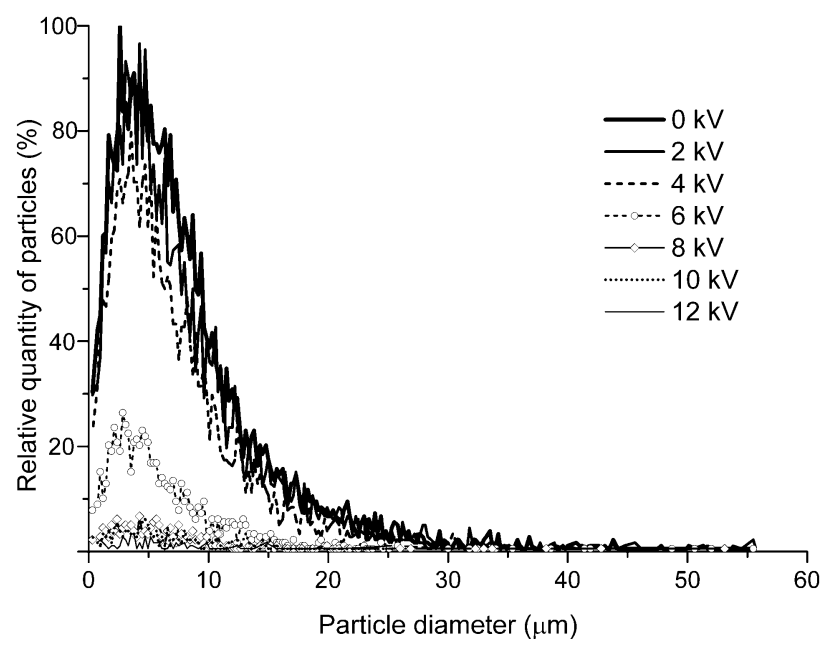

a

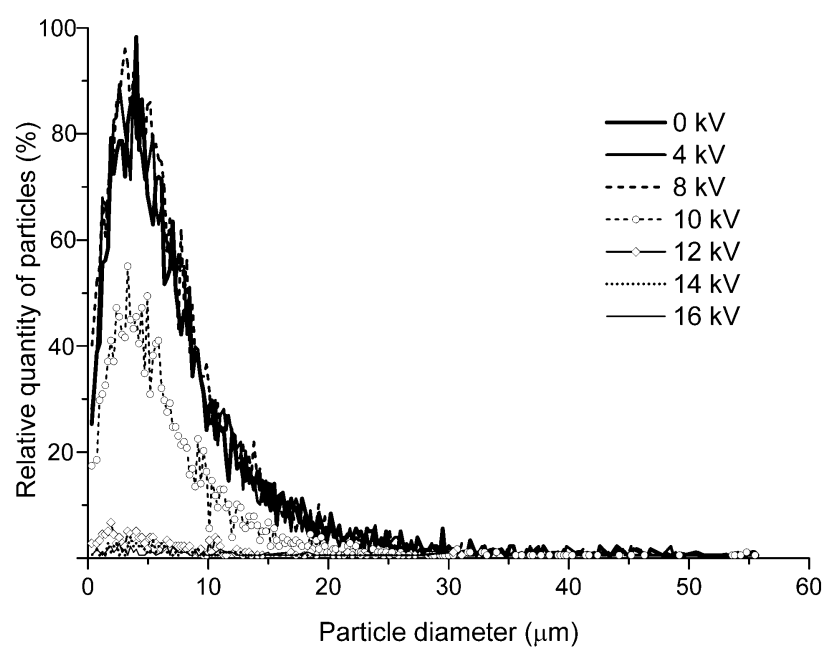

b

Fig. 3 Dependence of relative distribution of particles on the supplied voltage to the ESP in the case of negative (a) and positive (b) potentials of the ESP at flue gas $R e$ number 25000

A slightly different situation was observed for the positive potential (Fig. 3, b). A stepwise increase of the voltage from $0 \mathrm{kV}$ to $\sim 8 \mathrm{kV}$ did not give any remarkable decrease in the particle quantity; therefore, the distribution of the particles practically remained the same. A sudden decrease in particle quantity over all range of particles' diameters was observed only when the voltage was above $8 \mathrm{kV}$. With further increase of the voltage (more than
$12 \mathrm{kV}$ ), the particle quantity remained very small.

Examination of the fractional collection efficiency of the ESP is presented in Fig. 4. The fractional collection efficiency of the ESP $\left(E_{i}\right)$ was calculated based on the following equation [28]:

$$
E_{i}=\left(1-N_{f i} / N_{i}\right) \times 100
$$

where $N_{f i}$ is the quantity of the particles with the diameter $i$ obtained using the ESP; $N_{i}$ is the quantity of the particles with the same diameter $i$ obtained without the ESP.

Fig. 4 shows that at voltages $\sim 4 \mathrm{kV}$ for a negative potential and $\sim 8 \mathrm{kV}$ for a positive potential there is some cleaning of the flue gases. This could be related to partial charging of the particles in the boiler.

At the voltage of $\sim 6 \mathrm{kV}$ for the negative and $\sim 10 \mathrm{kV}$ for a positive potential, a sharp increase in the collection efficiency already occurs. This effect is more expressed for a positive potential. The results also show that the collection of the larger particles $(\geq 15 \mu \mathrm{m})$ is more efficient compared to the smaller particles.

Further increase of the voltage (above $12 \mathrm{kV}$ ) gave only a negligible increase in the collection efficiency, which already did not depend on the potential (negative/positive) in the ESP.

In general, the results presented in Fig. 4 demonstrate that small particles are also effectively collected when the applied voltage to the ESP is higher.

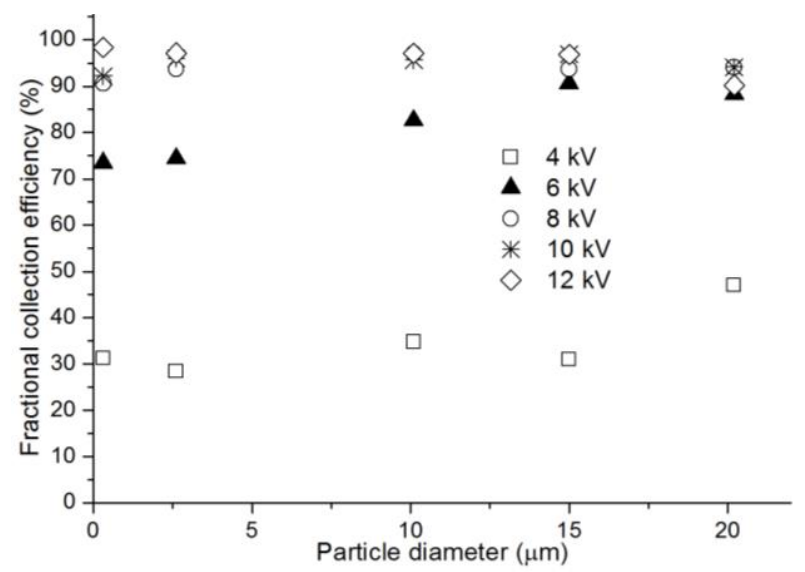

a

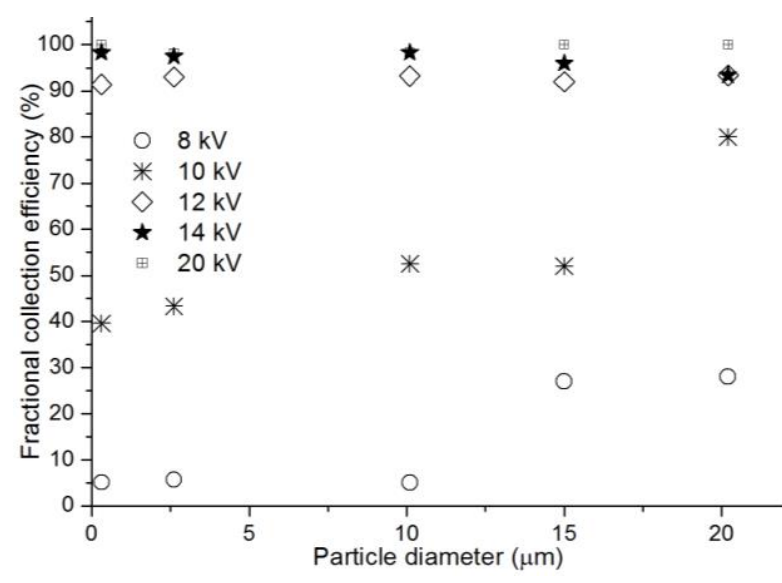

b

Fig. 4 Variation of fractional collection efficiency of particles with applied negative (a) and positive (b) potentials to the ESP at flue gas $R e$ number 25000 
Comparison of the ESP fractional collection efficiency in the case of a negative potential for different $R e$ numbers is presented in Fig. 5. Some stratification of the data depending on $R e$ number is noticed only at $6 \mathrm{kV}$ voltage. The highest collection efficiency is in the case of the smallest $R e$ number $(R e=4200)$. At high voltages the dependence of the collection efficiency on $R e$ number is insignificant.

The data in the case of a positive potential (Fig. 6) demonstrate rather significant dependence on the $R e$ number for voltages of 8 and $10 \mathrm{kV}$. And it is necessary to indicate that the collection efficiency dependence on the $R e$ number is increasing with decreasing of the diameter of the particles. At higher voltages $(12,14 \mathrm{kV})$, there is no dependence of the collection efficiency on the Re number in the whole spectrum of the particles diameter and collection efficiency reaches $90-100 \%$. Such behavior of the particles could be explained by importance of the inertial forces of the particles and flow turbulence at smaller $R e$ numbers.

In Fig. 7, comparison of the total collection efficiency of the particles with supplied voltage to the ESP and different flue gas $R e$ numbers in the ESP (i.e., different number of collecting electrodes) in the case of negative and positive potentials is presented.

The total collection efficiency of the $\operatorname{ESP}\left(E_{T}\right)$ was calculated based on the following equation:

$$
E_{T i}=\left(1-C_{i} / C_{o}\right) \times 100,
$$

where $C_{o}$ - concentration of the particles obtained without the ESP; $C_{i}$ - concentration of the particles obtained with the ESP at a certain voltage.

The results show that in the case of a positive potential in the region of smaller voltages till $12 \mathrm{kV}$, collection efficiency depends significantly on the flue gas $R e$ number in the ESP. So in fact, some shift of the corona discharge to smaller voltages is observed for smaller $R \mathrm{e}$ numbers (at $9-10 \mathrm{kV}$ for $R e=25000$ but at $7-8 \mathrm{kV}$ for $R e=4200$ ). At higher voltages, the results almost do not depend on the flue gas $R e$ number in the ESP.

In the case of a negative potential, the effect of the $R e$ number is insignificant and corona discharge is practically at the same voltage $(4-5 \mathrm{kV})$ for whole range of $R e$ numbers investigated but it is at smaller voltages than in the case of a positive potential.

Variation of the total collection efficiency of the particles with power of the ESP was also analyzed. The power of the ESP $(P)$ was obtained by multiplying the current and the voltage supplied to the discharge electrode of the ESP. A slight increase of power till $\sim 0.5 \mathrm{~W}$ in the case of a negative potential shows that the total collection efficiency increases to approx. $94-96 \%$. The further increase of power $(\geq 1 \mathrm{~W})$ indicates only a slight increase in collection efficiency.

Very similar total collection efficiency distribution with an increase of power was obtained in the case of a positive potential. Some shift of the results to the region of higher power is observed but even at low power $(\sim 4 \mathrm{~W})$ the total collection efficiency of the ESP was about $98-99 \%$.

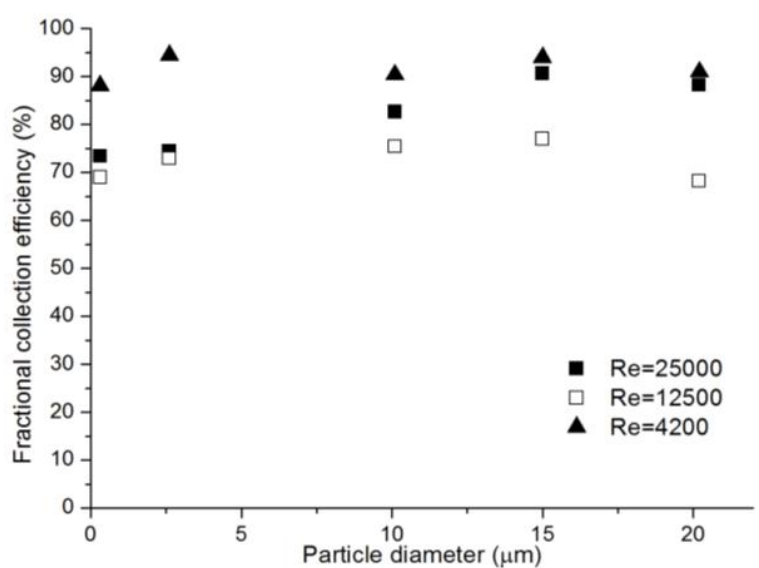

a

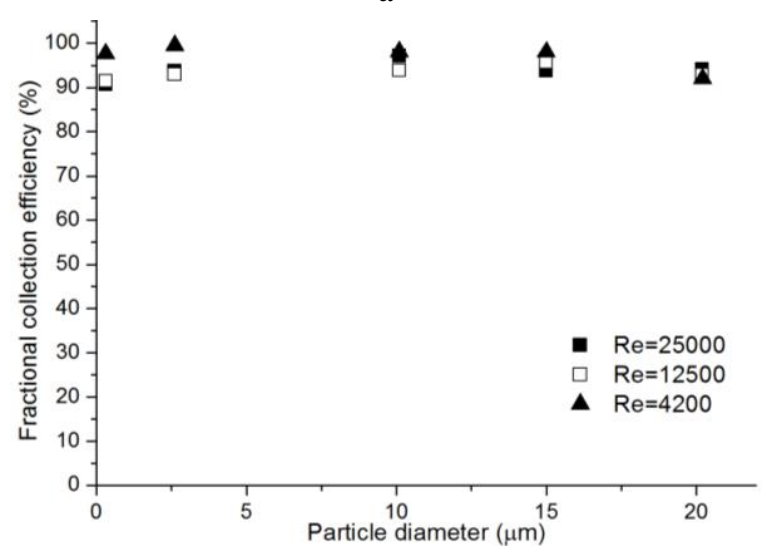

b

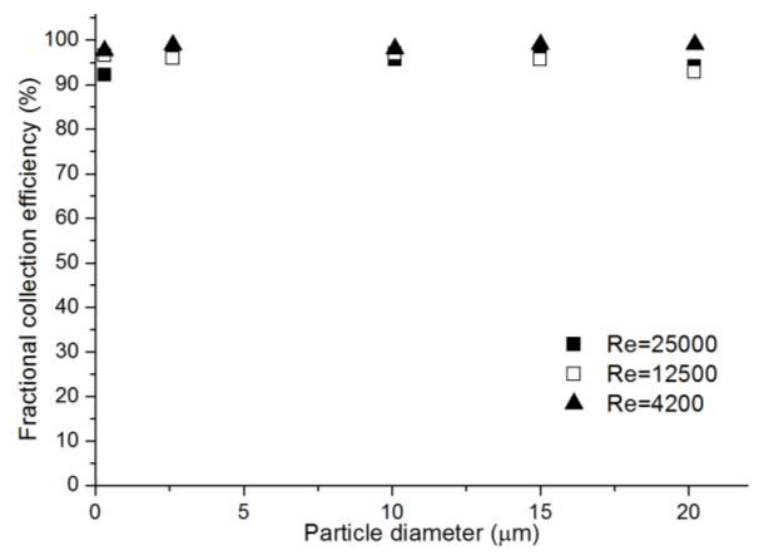

c

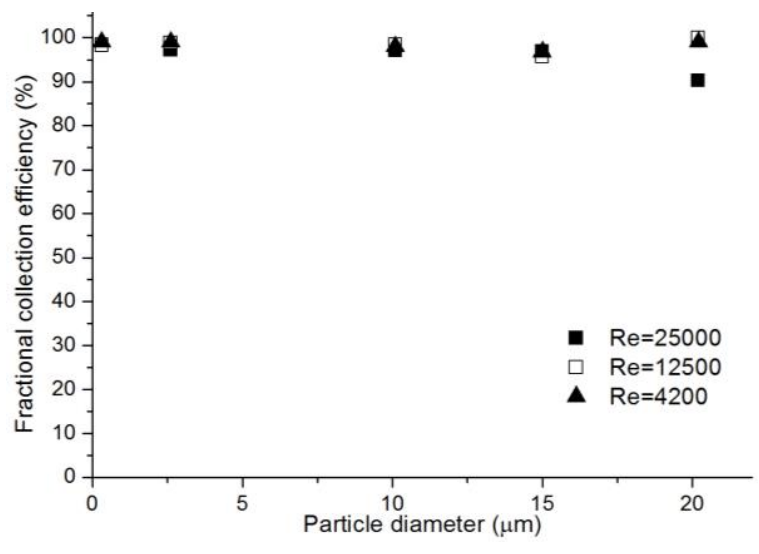

d

Fig. 5 Comparison of fractional collection efficiency of particles with the applied negative potential to the ESP for different $R e$ numbers: a $-6 \mathrm{kV}$; b $-8 \mathrm{kV}$; $\mathrm{c}-10 \mathrm{kV} ; \mathrm{d}-12 \mathrm{kV}$ 


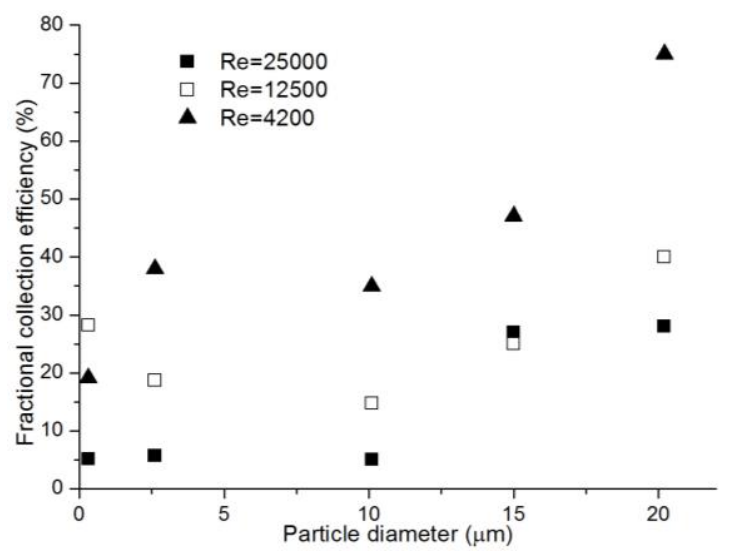

a

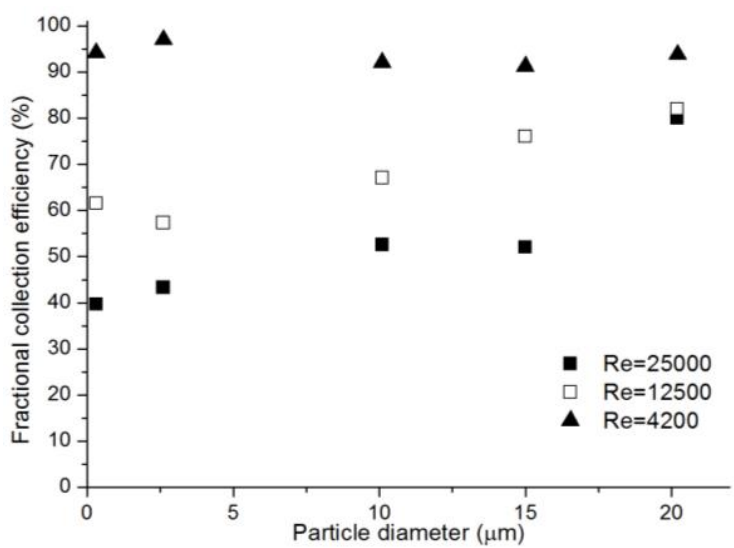

$\mathrm{b}$

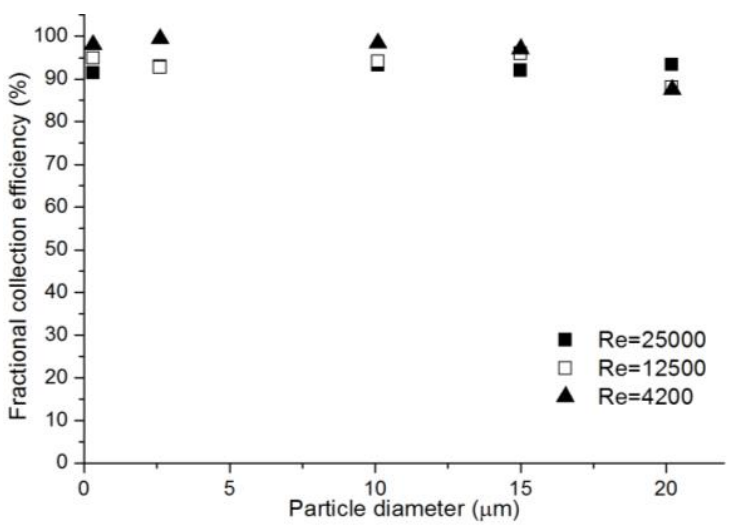

c

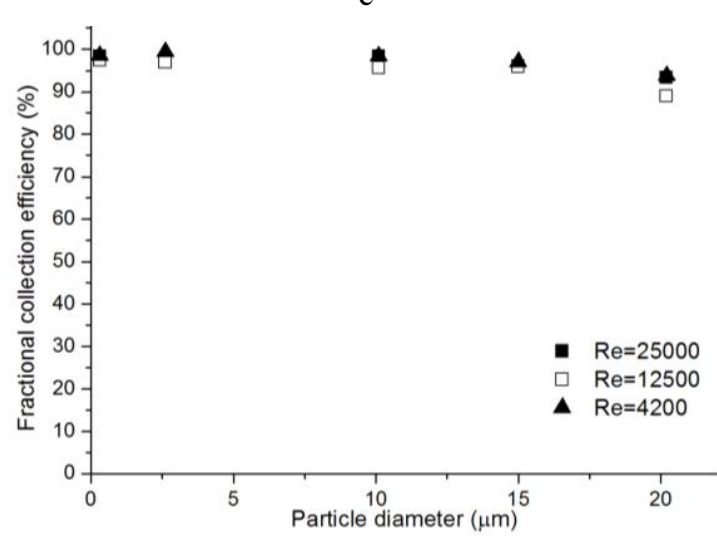

d

Fig. 6 Comparison of fractional collection efficiency of particles with the applied positive potential to the ESP for different Re numbers: a $-8 \mathrm{kV} ; \mathrm{b}-10 \mathrm{kV}$; $\mathrm{c}-12 \mathrm{kV} ; \mathrm{d}-14 \mathrm{kV}$

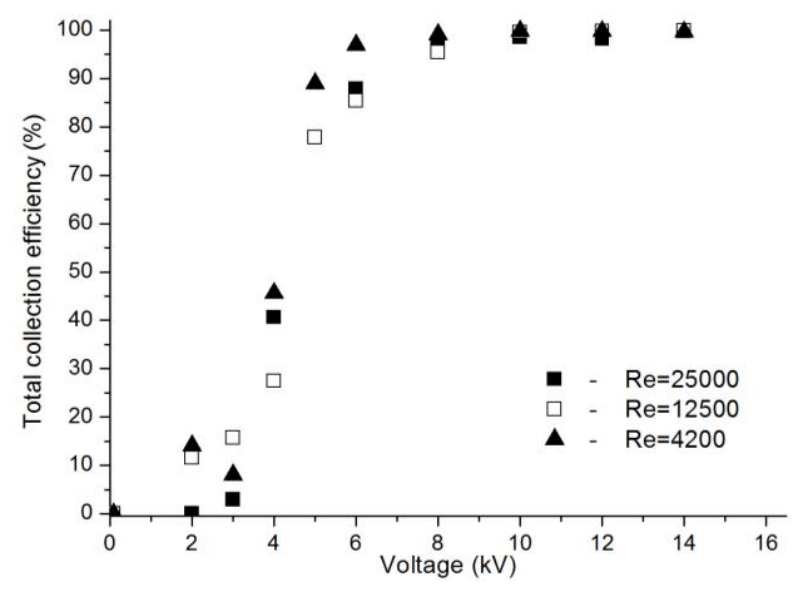

a

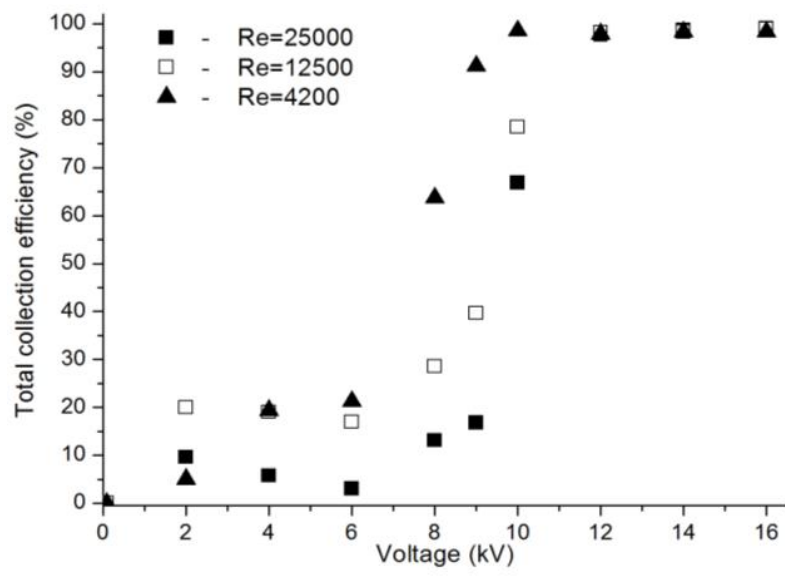

b

Fig. 7 Comparison of the total collection efficiency of particles with the supplied voltage to the ESP in the case of negative (a) and positive (b) potentials at different $R e$ numbers

\section{Conclusions}

The complex investigations of gaseous emissions and emissions of solid particles in flue gases from a class 3 residential boiler in the case of biofuel combusting under a stable combustion regime and application of an ESP in different operating modes allow the following conclusions to be drawn:

1. Without the ESP, the emissions of the solid particles normalised for the reference $\mathrm{O}_{2}$ value were $\sim 13 \mathrm{mg} / \mathrm{Nm}^{3}$. The gaseous emissions and the emissions of the solid particles were much lower than the recommended limiting values for a boiler of such class.

2. Without the ESP, the solid particles mainly with diameters from $0.4 \mu \mathrm{m}$ to $\sim 20 \mu \mathrm{m}$ were determined in the flue gases, while the peak diameter was $\sim 4 \mu \mathrm{m}$.

3. At smaller voltages in the case of a positive potential, the fractional collection efficiency of the ESP is increasing with increasing diameter of the particles and the $R e$ number. For a negative potential such dependence is much less expressed.

4. In the case of a negative potential, the corona discharge is at smaller voltages compared with the case of a positive potential and practically does not depend on the $R e$ number. However, for a positive potential, the corona discharge is shifting to smaller voltages with decreasing of 
the $R e$ number.

5. After the corona discharge, fractional and total collection efficiency in both cases practically does not depend on the flue gas $R e$ number. The total collection efficiency of the ESP was about $98-99 \%$ even at low power $(\sim 4 \mathrm{~W})$.

\section{References}

1. Kasurinen, S.; Jalava, P.I.; Tapanainen, M.; Uski, O.; Happo, M.S.; Paakkanen, J.M.; Lamberg, H.; Koponen, H.; Nuutinen, I.; Kortelainen, M.; Jokiniemi, J.; Hirvonen, M.R. 2015. Toxicological effects of particulate emissions - A comparison of oil and wood fuels in small and medium scale heating systems, Atmospheric Environment 103: 321-330. http://dx.doi.org/10.1016/j.atmosenv.2014.12.055.

2. Hogan, M.; Otterstedt, J.; Morin, R.; Wilde, J. 2010. Biomass for heat and power-opportunity and economics.

3. European bioenergy outlook 2013. Statistical report, Aebiom.

4. Pleckaitiene, R.; Buinevicius, K.; Puida, E. 2013. Analysis of solid phase nitrogen conversion process to gaseous oxides, Mechanika 19(5): 531-538. http://dx.doi.org/10.5755/j01.mech.19.5.5543.

5. Survey of the present state of particle precipitation devices for residential biomass combustion with a nominal capacity up to $50 \mathrm{~kW}$ in IEA Bioenergy TASK32. 2011, Institute for Process and Particle Engineering,Graz University of Technology, Austria.

6. Maenhaut, W.; Fernández-Jiménez, M.T.; Lind, T.; Kauppinen, E.I.; Valmari, T.; Sfiris, G.; Nilsson, K. 1999. In-stack particle size and composition transformations during circulating fluidized bed combustion of willow and forest residue, Nuclear Instruments and Methods in Physics Research Section B: Beam Interactions with Materials and Atoms 150(1-4): 417-421. http://dx.doi.org/10.1016/S0168-583X(98)01068-4.

7. Johansson, L.S.; Leckner, B.; Gustavsson, L.; Cooper, D.; Tullin, C.; Potter, A. 2004. Emission characteristics of modern and old-type residential boilers fired with wood logs and wood pellets, Atmospheric Environment 38: 4183-4195. http://dx.doi.org/10.1016/j.atmosenv.2004.04.020.

8. Obernberger, I.; Brunner, T.; Bärnthaler, G. 2007. Fine particulate from modern Austrian small-scale biomass combustion plants, Proc. 15th European biomass conference and exhibition. Berlin.

9. Aerosols in fixed-bed biomass combustion - formation, growth, chemical composition, deposition, precipitation and separation from flue gas, Final report, Graz University of Technology 2003. Available from Internet: http://www.bios-bioenergy.at/uploads/media/ReportBioaerosols-2004-03-28.pdf

10. Wierzbicka, A.; Lillieblad, L.; Pagels, J.; Strand, M.; Gudmundsson, A.; Gharibi, A.; Swietlicki, E.; Sanati, M.; Bohgard, M. 2005. Particle emissions from district heating units operating on three commonly used biofuels, Atmospheric Environment 39: 139-150. http://dx.doi.org/doi:10.1016/j.atmosenv.2004.09.027.

11. Parker, K.R. 1997. Applied Electrostatic Precipitation,
London: Chapman \& Hall, 522 p.

12. Varonos, A.A.; Anagnostopoulos, J.S.; Bergeles, G.C. 2002. Prediction of the cleaning efficiency of an electrostatic precipitator, Journal of Electrostatics 55(2): 111-133.

http://dx.doi.org/10.1016/S0304-3886(01)00187-5.

13. Chang, C.L.; Bai, H. 1999. An experimental study on the performance of a single discharge wire-plate electrostatic precipitator with back corona, Journal of Aerosol Science 30(3): 325-340.

http://dx.doi.org/10.1016/S0021-8502(98)00064-0.

14. Kuroda, Y.; Kawada, Y.; Takahashi, T.; Ehara, Y.; Ito, T.; Zukeran, A.; Kono, Y.; Yasumoto, K. 2003. Effect of electrode shape on discharge current and performance with barrier discharge type electrostatic precipitator, Journal of Electrostatics 57(3-4): 407-415. http://dx.doi.org/10.1016/S0304-3886(02)00177-8

15. Kim, J.H.; Lee, H.S.; Kim, H.H.; Ogata, A. 2010. Electrospray with electrostatic precipitator enhances fine particles collection efficiency, Journal of Electrostatics 68(4): 305-310. http://dx.doi.org/10.1016/j.elstat.2010.03.002.

16. Nowak, A. 2012. Vibration of collecting electrodes in electrostatic precipitators - Modelling, measurements and simulation tests, Journal of Electrostatics 70(3): 327-332.

http://dx.doi.org/10.1016/j.elstat.2012.04.004.

17. Vares, V. 2007. Manual for Biofuel Users, Tallinn University of Technology.

18. Intra, P.; Limueadphai, P.; Tippayawong, P. 2010. Particulate emission reduction from biomass burning in small combustion systems with a multiple tubular electrostatic precipitator, Particulate Science and Technology 28(6): 547-565. http://dx.doi.org/10.1080/027263510037584.

19. Bologa, A.; Paur, H.R.; Ulbricht, T.; Woletz, K. 2010. Particle emissions from small scale wood combustion devices and their control by electrostatic precipitation, Chemical Engineering Transactions 22: 119124. http://dx.doi.org/10.3303/CET1022019.

20. Schmatloch, V.; Rausch, S. 2005. Design and characterisation of an electrostatic precipitator for small heating appliances, Journal of Electrostatics 63(2): 85-100. http://dx.doi.org/10.1016/j.elstat.2004.08.001.

21. Bologa, A.; Paur, H.R.H.; Seifert, H.; Woletz, K.; Ulbricht, T. 2010. Fine particle generation, evolution and control by small scale biomass combustion devices, Proc. 18th European Biomass Conference and Exhibition, Lyon, Frankreich.

22. Pettersson, J.; Strand, M.; Lin, L. 2011. Chargingand removal efficiency of an ESP in a $250 \mathrm{~kW}$ biomass boiler, Proc. XII International Conference on Electrostatic Precipitation, ICESP Nürnberg. http://dx.doi.org/10.3846/1648-6897.2008.16.97-103.

23. Omara, M.; Hopke, P.K.; Raja, S.; Holsen, T.M. 2010. Performance evaluation of a model electrostatic precipitator for an advanced wood combustion system, Energy Fuels 24(12): 6301-6306. http://dx.doi.org/10.1021/ef101031u.

24. Bologa, A.; Paur, H.R.H.; Seifert, H.; Wascher, T. 2005. Pilot-plant testing of a novel electrostatic collec- 
tor for submicrometer particles, Industry Applications, IEEE Transactions 41(4): 882-890.

25. Davidson, T.A. 1993. A Simple and accurate method for calculating viscosity of gaseous mixtures, Report of Investigations 9456, United States Department of the Interior.

26. Vonžodas, T.; Pedišius, N.; Valantinavičius, M. 2013. Investigation of performance parameters of low capacity water boilers burning biofuel, Power Engineering 59(2): 93-103 (in Lithuanian).

27. Ehrlich, C.; Noll, G.; Kalkoff, W.D.; Baumbach, G.; Dreiseidler, A. 2007. Emissions from industrial plants - Results from measurement programmes in Germany, Atmospheric Environment 41(29): 6236-6254. http://dx.doi.org/10.1016/j.atmosenv.2007.03.059.

28. Mussati, D.C. 2002. EPA air pollution control cost manual (Sixth Edition), Research Triangle Park, 752 p.
R. Poškas, A. Sirvydas, P. Poškas, V. Šimonis, J. Jankauskas

\section{INVESTIGATION OF THE ESP CLEANING EFFICIENCY OF THE FLUE GASES IN THE WIDE RANGE OF $R e$ NUMBERS}

\section{S u m m a r y}

The aim of this work is to evaluate the emissions from a residential boiler $(50 \mathrm{~kW})$ and to investigate the properties of an electrostatic precipitator capturing the solid particles emitted during incineration of wood pellets in wide range of flue gas $R e$ numbers $(R e=4200-25000)$. The performed analysis demonstrated that in the case of a negative potential, the corona discharge is at smaller voltages than in the case of a positive potential and practically does not depend on the Re number. However, in the case of a positive potential, dependence on the $R e$ number is obvious and the corona discharge is shifting to smaller voltages with decreasing of the $R e$ number.

Keywords: small boilers, flue gases, solid particles, electrostatic precipitator, different $R e$ numbers.

Received February 22, 2016

Accepted February 06, 2017 